\title{
SCIENTIFIC REPORTS

\section{OPEN Metabolic profile and behavior of clethodim and spirotetramat in herbs during plant growth and processing under controlled conditions}

\begin{abstract}
Magdalena Jankowska ${ }^{*}{ }^{*}$, Piotr Kaczyński \& Bożena Łozowicka
Herbs may contain pesticide residues which are an important discriminator of food security and food quality. The challenge of the research was to assess the fate of the herbicide clethodim (CLE) and the insecticide spirotetramat (SPI) applied in herbs (BBCH 11-21) during herb growth and processing under controlled greenhouse trial conditions. The metabolic profile of CLE and SPI and their degradation products in basil (Ocimum basilicum L.), peppermint (Mentha $\times$ piperita L.) and sage (Salvia officinalis L.) was also presented. The half-lives of CLE and SPI in herbs were 1.10-1.56 days and 0.51-0.83 days, respectively. The terminal residues of SPI (SPI-enol, SPI-ketohydroxy, SPI-monohydroxy and SPIenol-glucoside) and CLE (CLE-sulfone and CLE-sulfoxide) in herbal matrices were measured below EU maximum residue limits. In this paper, we aimed to assess the impact of washing and dehydratation pretreatment and calculated processing factors (PFs) which can be applied to more accurate food safety assessments. The PF values of CLE and SPI after drying prior washing was below 1 indicating reduction of initial residues. Drying process without washing demonstrated increases of SPI concentrations (PF up to 1.50). The lowest PFs were obtained when raw herbal plants were washed before drying showing almost complete degradation of parent compound (93-99\%).
\end{abstract}

Herbal plants are widely used fresh materials for the food and health industries, especially dried herbs and spices are popular for consumers because they have multiple phytochemical properties ${ }^{1}$. These include phenolic compounds, alkaloids, flavonoids, anthocyanidins, cardenolides or tannins ${ }^{2}$. In addition to these essential and valuable substances, herbs contain contaminants, especially pesticide residues which are a critical discriminator of food quality and safety ${ }^{3}$. Pesticides belong to substances toxic for humans and some of them are mutagenic, teratogenic, carcinogenic and allergenic and persistent in the environment (they are not easily decomposed, they have the possibility of bioaccumulation and migration $)^{4}$.

The maximum acceptable levels have been unified by various international organizations to assure the safety of raw herb commodities used as pharmaceutical products or food ${ }^{5-8}$. According to a report from the European Food Safety Authority ${ }^{9}, 65.1 \%$ of the analyzed herbs contained mainly organophosphate and pyrethroid insecticides, $9.4 \%$ exceeded the Maximum Residue Limits set by the EU (MRLs $=0.01 ; 0.05 \mathrm{mg} / \mathrm{kg}$ ). In herbal samples, insecticides (organophosphorus, chloroorganic and pyrethroid), fungicides and herbicides are detected at average concentration levels from $0.01 \mathrm{mg} / \mathrm{kg}$ up to $2.0 \mathrm{mg} / \mathrm{kg}^{10-15}$.

Clethodim is cyclohexanedione herbicide very often used for the selective control of the monocotyledonous weeds such as millet, thick oats in herbal plants. Insecticide, spirotetramat belongs to tetramic acid family and is very commonly used against aphids because herbal plants are very often attracted by this insect (Table S1). After these pesticides application, metabolic pathways and degradation processes may modify the toxicological properties of the active substance ${ }^{16}$. In some instances metabolites are more toxic and consequently pose a greater risk to the environment than the parent compound. Clethodim and spirotetramat both have a complex residue definition (CLE sum of clethodim, CLE-sulphoxide and CLE-sulphone and their 5-hydroxy conjugates; SPI sum 
of spirotetramat, (BYI08330) SPI-enol, SPI-ketohydroxy, SPI-monohydroxy and SPI-enol-glucoside). Only limited information on the toxicological properties of CLE/SPI-metabolites is available and are presented in citrus, Appiacea and Brassicaceae vegetables, colza and soil ${ }^{17,18}$. Thus, it is of great significance to evaluate the metabolic profile of CLE and SPI and their behavior during plant growth and processing. The combined exposure of CLE/ SPI and contribution of individual metabolites is needed in the toxicological characterization to make more accurate food safety assessments.

Herbs are commonly used medicinal means as a complementary or an alternative form of healthcare and are considered to be safe ${ }^{19}$. The World Health Organization (WHO) survey presented that most populations rely on non-conventional herbal medicines. Despite the presence of many health benefits of herbs, many contaminates in fresh commodities during cultivation, harvesting, processing and storage can occur and make their consumption unsafe $^{19}$.

Technological processing is the method that changes the concentration of toxic substances in the processed product $^{20-22}$. It might completely reduce the concentration, have no lack of influence and sometimes increase the levels in the final product ${ }^{23-25}$. Herbal raw materials, due to their short durability and seasonality, undergo various thermal treatments. Drying is the oldest method of preservation of food and the most frequently used way of preserving herbs that is the basis for their further use. It allows extending the durability of herbal products, preserving their taste, aroma, as well as many pro-health properties ${ }^{26,27}$.

The improvement of living standards showed that people increasingly care more about their health and pay attention to food safety. Herbs, especially in the dried form of e.g. spices, teas, pharmaceutical and cosmetics product are very popular for consumers ${ }^{28}$. Drying significantly reduces pesticide residues, regardless of whether the material is exposed to solar radiation or using drying equipment ${ }^{29}$. Thus, development of processing technologies for reduction of toxic substances in herbal commodities was a priority for this research.

To our best knowledge, the effect of food processing on CLE/SPI in herbs was not studied. The scientific literature is focused on individual groups of compounds (mainly organophosphorus) during the preparation of herbal infusions or cooking herbs ${ }^{29-31}$. The above facts clearly indicate that nowadays, it is an extremely important goal to evaluate the behavior of clethodim and spirotetramat.

Therefore, the science aim of the study was to: (1) evaluate metabolic profile of the cyclohexanedione herbicide and the tetramic acid insecticide in herbs during plant growth; (2) present dissipation dynamics of CLE and SPI in fresh basil, peppermint and sage (Ocimum basilicum L., Mentha $\times$ piperita L. and Salvia officinalis L.) and determine the half-lives; (3) investigate the residual of these pesticides and metabolites during processing of fresh herbal plants; (4) calculate the PFs of sum CLE and sum SPI in washing/drying process regarding to EU residue definition and (5) an additional scientific aspect of the work will be supplementation PFs databases for the first time for herbs.

\section{Results and Discussion}

Method performance. A modified QuEChERS method for simultaneous determination of SPI and CLE and their six metabolites in various species of herbal plants was applied followed by LC-MS/MS. The average recoveries of spirotetramat/SPI-metabolites in fresh and dried matrices were within $85-101 \%$ and $87-96 \%$, respectively while for clethodim/CLE-metabolites in the range of $80-108 \%$ and $74-102 \%$, respectively. These values were within the range expected for residue analysis. The reproducibility of recovery results, as indicated by relative standard deviations (RSDs) $<20 \%$, confirmed that the method is sufficiently reliable for pesticide analysis in this study ${ }^{32}$. The calibration curve was linear over the concentration range with determination coefficients $\mathrm{R}^{2}>0.995$. The limit of detection (LOD) was $0.005 \mathrm{mg} / \mathrm{kg}$ whereas limit of quantification (LOQ) was $0.001 \mathrm{mg} / \mathrm{kg}$ for spirotetramat and clethodim and their metabolites.

Metabolic profile - fate of clethodim. The initial residues of herbicide clethodim after $1 \mathrm{~h}$ of application in basil, peppermint and sage were $3.897 \mathrm{mg} / \mathrm{kg}, 4.251 \mathrm{mg} / \mathrm{kg}$ and $4.197 \mathrm{mg} / \mathrm{kg}$, respectively (Table 1).

Fate of clethodim and its metabolites in three species of herbal plants is presented in Fig. 1a-c. The residues of total clethodim (CLE, CLE-sulfone and CLE-sulfoxide) in basil, peppermint and sage decreased to $0.336 \mathrm{mg} / \mathrm{kg}$, 0.055 and $0.150 \mathrm{mg} / \mathrm{kg}$, respectively, indicated that were below MRL $0.50 \mathrm{mg} / \mathrm{kg}$ established by European Union. Under controlled conditions clethodim rapidly degraded in herbs and converted into its oxidation metabolites CLE-sulfoxide and CLE-sulfon. As presented in the Fig. 1a-c, CLE and CLE-sulfoxide concentration decreased gradually with time elapse giving over $90 \%$ to complete degradation, while CLE-sulfone showed a tendency of rapidly increasing first (the highest concentration observed at second day up to $0.50 \mathrm{mg} / \mathrm{kg}$ ) and continuous decreasing (after 21 days of herbs growth below $0.10 \mathrm{mg} / \mathrm{kg}$ ). The dissipation rate of CLE in basil, peppermint and sage fitted to first-order kinetics $\left(\mathrm{R}^{2}=0.9011 ; 0.9238\right.$ and 0.9285 , respectively) with dissipation equation: $y=2,6677 \mathrm{e}^{-0,443 \mathrm{x}}$ in basil; $\mathrm{y}=2,5637 \mathrm{e}^{-0,688 \mathrm{x}}$ in peppermint and $\mathrm{y}=4,5925 \mathrm{e}^{-0,527 \mathrm{x}}$ in sage and the half-life of clethodim was $1.56,1.10$ and 1.38 days. Dissipation pathway of CLE in soil samples collected from the herbal plants cultivation proved that CLE rapidly converted to its sulfoxide in all cases (CLE and CLE-sulfone residues lower than LOQ). The initial concentration of CLE-sulfoxide in soil was below $0.250 \mathrm{mg} / \mathrm{kg}$ and reduced to below $0.010 \mathrm{mg} / \mathrm{kg}$ (more than 95\%) after 21 days after application with the half-lives in the range of 4.1-4.5 days.

Our results are consistent with You et al. ${ }^{17}$ who showed that clethodim sulfoxide dissipated quickly in rape plant and soil with half-lives of about 4-4.3 days. CLE-sulphone similarly increased initially then decreased in rape plant but was not detected in soil. According to $\mathrm{PPDB}^{33}$ clethodim degradation is 3 days in soil (DT50 field). Clethodim sulfoxide and sulphone are mainly formed in soil with estimated maximum occurrence fraction 0.76 and 0.16 , respectively, Interestingly, Sandin-Espana et al. ${ }^{34}$ reported very rapid photodegradation of clethodim and and its metabolite sethoxydim obtained on silica gel plates in soil and plant surface model systems under simulated solar radiation with half-lives of $1.8 \mathrm{~min}$ and $5.0 \mathrm{~min}$, respectively. 


\begin{tabular}{|c|c|c|c|}
\hline \multirow[b]{3}{*}{ Days } & \multirow{2}{*}{\begin{tabular}{|l|} 
Parent substance \\
clethodim
\end{tabular}} & \multicolumn{2}{|l|}{ Metabolites } \\
\hline & & sulfone & sulfoxide \\
\hline & Mean $\mathrm{C} \pm \mathrm{SD} \mathbf{n}=\mathbf{3}$ & Mean $C \pm S D n=3$ & Mean $\mathrm{C} \pm \mathrm{SD} \mathbf{n}=3$ \\
\hline \multicolumn{4}{|c|}{ BASIL Ocimum basilicum L. } \\
\hline $0(1 \mathrm{~h})$ & $3.897 \pm 0.0034$ & $0.246 \pm 0.0056$ & $1.965 \pm 0.0046$ \\
\hline 1 & $0.728 \pm 0.0028$ & $0.504 \pm 0.0061$ & $1.257 \pm 0.0035$ \\
\hline 2 & $0.459 \pm 0.0046$ & $0.493 \pm 0.0021$ & $0.787 \pm 0.0043$ \\
\hline 3 & $0.293 \pm 0.0054$ & $0.305 \pm 0.0029$ & $0.505 \pm 0.0028$ \\
\hline 7 & $0.270 \pm 0.0019$ & $0.239 \pm 0.0017$ & $0.299 \pm 0.0019$ \\
\hline 14 & $0.251 \pm 0.0022$ & $0.105 \pm 0.0026$ & $0.220 \pm 0.0015$ \\
\hline 21 & $0.151 \pm 0.0030$ & $0.046 \pm 0.0010$ & $0.139 \pm 0.0011$ \\
\hline \multicolumn{4}{|c|}{ PEPPERMINT Mentha $\times$ piperita L. } \\
\hline $0(1 \mathrm{~h})$ & $4.251 \pm 0.0042$ & $0.220 \pm 0.0036$ & $1.948 \pm 0.0068$ \\
\hline 1 & $0.203 \pm 0.0028$ & $0.316 \pm 0.0025$ & $0.602 \pm 0.0044$ \\
\hline 2 & $0.198 \pm 0.0033$ & $0.492 \pm 0.0029$ & $0.310 \pm 0.0026$ \\
\hline 3 & $0.175 \pm 0.0019$ & $0.318 \pm 0.0031$ & $0.373 \pm 0.0031$ \\
\hline 7 & $0.084 \pm 0.0023$ & $0.150 \pm 0.0016$ & $0.136 \pm 0.0027$ \\
\hline 14 & $0.060 \pm 0.0017$ & $0.079 \pm 0.0013$ & $0.078 \pm 0.0014$ \\
\hline 21 & $<$ LOQ & $0.033 \pm 0.0009$ & $0.022 \pm 0.0008$ \\
\hline \multicolumn{4}{|c|}{ SAGE Salvia officinalis $\mathrm{L}$. } \\
\hline $0(1 \mathrm{~h})$ & $4.197 \pm 0.0048$ & $0.221 \pm 0.0060$ & $2.437 \pm 0.0055$ \\
\hline 1 & $0.983 \pm 0.0052$ & $0.253 \pm 0.0042$ & $0.304 \pm 0.0021$ \\
\hline 2 & $0.917 \pm 0.0035$ & $0.431 \pm 0.0021$ & $0.112 \pm 0.0032$ \\
\hline 3 & $0.444 \pm 0.0031$ & $0.328 \pm 0.0044$ & $0.064 \pm 0.0011$ \\
\hline 7 & $0.447 \pm 0.0014$ & $0.302 \pm 0.0020$ & $0.026 \pm 0.0018$ \\
\hline 14 & $<$ LOQ & $0.204 \pm 0.0031$ & $0.009 \pm 0.0012$ \\
\hline 21 & $<$ LOQ & $0.086 \pm 0.0012$ & $0.006 \pm 0.0011$ \\
\hline
\end{tabular}

Table 1. Fate of clethodim in three species of herbs. Mean $\mathrm{C}$ - concentration for $\mathrm{n}=3(\mathrm{mg} / \mathrm{kg}) \pm \mathrm{SD}$ - standard deviation $(\mathrm{mg} / \mathrm{kg})$, LOQ - limit of quantification $(\mathrm{mg} / \mathrm{kg})$.

Metabolic profile - fate of spirotetramat. The initial residues of insecticide spirotetramat in basil, peppermint and sage after $1 \mathrm{~h}$ of application were $2.619 \mathrm{mg} / \mathrm{kg}, 3.830 \mathrm{mg} / \mathrm{kg}$ and $3.904 \mathrm{mg} / \mathrm{kg}$, respectively (Table 2).

Fate of spirotetramat and its metabolites in herbal plants is presented in Fig. 2a-d. Spirotetramat-monohydroxy was detected in trace amounts $(\leq 0.01 \mathrm{mg} / \mathrm{kg})$ in herbal plants.

The residues of spirotetramat (sum SPI, SPI-enol, SPI-ketohydroxy, SPI-monohydroxy and SPI-enol glucoside) in herbs were lower than EU MRL $4.00 \mathrm{mg} / \mathrm{kg}$. Finally, the concentration of basil, peppermint and sage decreased to $0.196 \mathrm{mg} / \mathrm{kg}, 0.030$ and $0.125 \mathrm{mg} / \mathrm{kg}$, respectively, which indicated that up to $99 \%$ of the initial concentrations reduced over the 21 days. Residues dissipated very fast during initial period followed by the first-order equation which provided the best fit to experimental data: $y=35.734 \mathrm{e}^{-1,351 \mathrm{x}}$ basil, $\mathrm{y}=43.029 \mathrm{e}^{-1,3413 \mathrm{x}}$ peppermint and $\mathrm{y}=15.357 \mathrm{e}^{-0,8388 \mathrm{x}}$ sage and correlation coefficients were $\mathrm{R}^{2}=0.9144,0.8893$ and 0.9369 , respectively. The half-life $\mathrm{t}_{1 / 2}$ of spirotetramat was $0.51,0.52$ and 0.83 days.

As presented in the Fig. 2b,c, SPI-enol (initial concentration $1.952 \mathrm{mg} / \mathrm{kg}$ in basil, $2.221 \mathrm{mg} / \mathrm{kg}$ in peppermint and $1.868 \mathrm{mg} / \mathrm{kg}$ in sage) decreased gradually with time, SPI-ketohydroxy (initial concentration $0.162 \mathrm{mg} / \mathrm{kg}$ in basil, $0.076 \mathrm{mg} / \mathrm{kg}$ in peppermint and $0.077 \mathrm{mg} / \mathrm{kg}$ in sage) increased first and then decreased below $0.20 \mathrm{mg} / \mathrm{kg}$ in all herbal species. Both, SPI-enol and SPI-ketohydroxy definitively indicated degradation of the parent compound. Meanwhile, SPI-enol-glucoside increased and decreased in varying degrees (concentration range from $0.08 \mathrm{mg} / \mathrm{kg}$ to $<\mathrm{LOD})$ and spirotetramat-monohydroxy was detected in trace amounts $(\leq 0.01 \mathrm{mg} / \mathrm{kg})$ in herbal plants. Dissipation study the SPI showed that SPI-ketohydroxy and SPI-enol was only detectable in soil collected from the herbs cultivation with initial deposits of $0.025 \mathrm{mg} / \mathrm{kg}$ and $0.061 \mathrm{mg} / \mathrm{kg}$, respectively. The half-lives ranged 2.1-2.8 days and completely reduced (99\%) after 21 days from application giving concentrations below $0.005 \mathrm{mg} /$ $\mathrm{kg}$. Residues of SPI-monohydroxy and SPI-enol glucoside metabolites were no detectable in soil $(<\mathrm{LOQ})$.

Similar results reported Zhang et al. ${ }^{35}$ showed the first order model for the dissipation of spirotetramat. The half-lives in citrus and soil were in the range of 2.3-8.5 days. However, Łozowicka et al. ${ }^{18}$ reported DT50 values of the SPI in Appiacea and Brassicaceae vegetable roots and leaves were 2.8-2.9 days and 2.1-2.4 days and in soil 0.2 day, respectively.

Distribution of clethodim and spirotetramat during processing. The change of concentration levels of SPI and CLE were investigated during three processes: washing, drying and washing with drying. The processing factors were assessed for each parent compound, metabolite and also taking into account a sum of parent compound and metabolites expressed as a total residue (Table 3 ). 
(a)

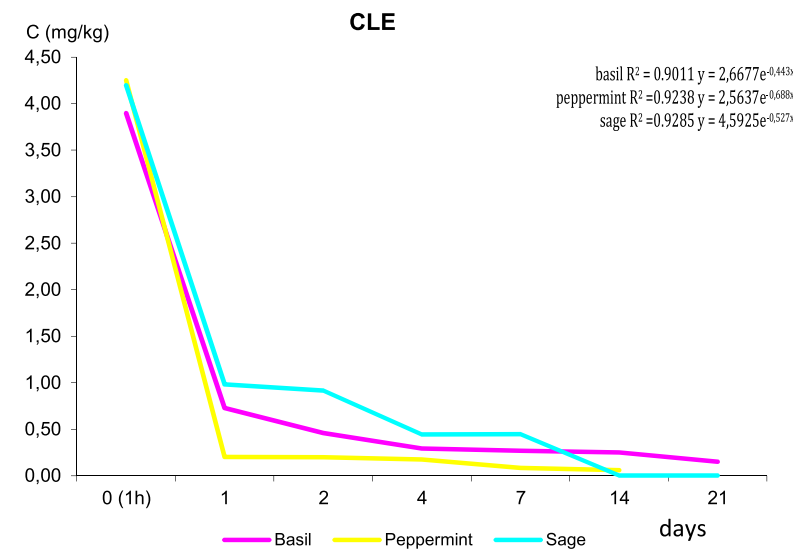

(b)

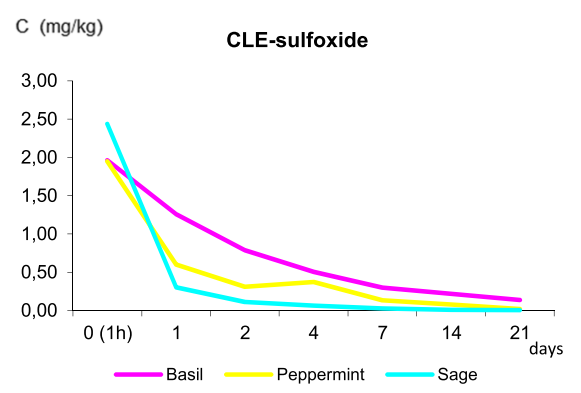

(c)

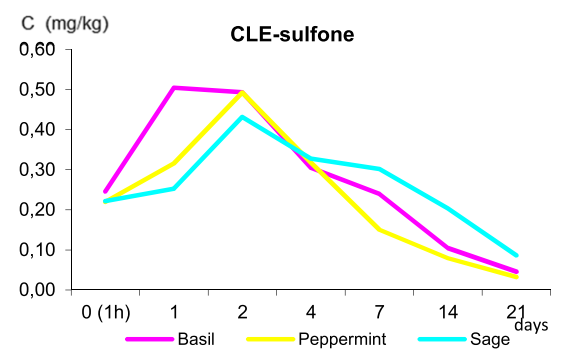

Figure 1. Changes in the concentration of clethodim (CLE) in three species of herbs. (a) CLE, (b) CLEsulfoxide, (c) CLE-sulfone.

The effect of processing and PFs. The main purpose of the drying operation is to efficiently decrease the high water content of the harvested spices to a safe level in order to get a stable, safe and good quality product ${ }^{27}$.

The processing factor $(\mathrm{PF})$ is the main parameter indicating the changes of pesticide residue level during processing. The calculated PF values for total clethodim after processing were all less than $1(\mathrm{PFs}=0.14-0.54)$ indicating reduction in the processed herbs. The initial concentrations of CLE and its two metabolites indicated that $5-6 \%$ of clethodim transformed to clethodim sulfone and $46-53 \%$ to clethodim sulfoxide. The processing factors for spirotetramat total were calculated for parent compound and its two metabolites B-ketohydroxy and B-enol because B- enol glucoside and B-monohydroxy were not detected in processed samples. The initial concentrations of spirotetramat and its metabolites indicated that $2-4 \%$ of spirotetramat transformed to its B-ketohydroxy and $48-58 \%$ to B-enol metabolite. PF values of total spirotetramat were in the range of PFs $=0.27-1.50$.

Herbs, like other food, undergo the washing step prior to consumption or further processing, it could be expected for pesticides, especially those with limited movement and penetration ability and with a high tendency of loosely maintaining at outer surface, to be removed with reasonable efficiency by this preparatory step $^{36}$. The effectiveness of washing depends on pesticide solubility in water or in different chemical solvents. Thus, clethodim has a good penetrating ability due to its hydrophilic property characterized by high solubility in water $(5450 \mathrm{mg} / \mathrm{L})$ and was more easily to remove from basil, peppermint and sage with reduction up to $51 \%$ $(\mathrm{PFs}=0.49-0.54)$ than slighty soluble spirotetramat (solubility in water at $20^{\circ} \mathrm{C}, 55 \mathrm{mg} / \mathrm{L}$ ) with the loss of residues from $32 \%$ to $41 \%(\mathrm{PFs}=0.59-0.68)$. The obtained results are consistent with our previous work, in which we have demonstrated that the solubility played a significant role in pesticide removal. Compounds soluble in water (e.g. acetamiprid $2950 \mathrm{mg} / \mathrm{L} \mathrm{PF}=0.43$ ) were more susceptible to elimination during washing fruit and vegetables in contrast to insoluble lambda-cyhalothrin $(0.005 \mathrm{mg} / \mathrm{L}, \mathrm{PF}=0.94)^{37}$. 


\begin{tabular}{|c|c|c|c|c|c|}
\hline \multirow{3}{*}{$\begin{array}{l}\text { Days after } \\
\text { treatment }\end{array}$} & \multirow{2}{*}{\begin{tabular}{|l|} 
Parent substance \\
Spirotetramat (SPI) \\
\end{tabular}} & \multicolumn{4}{|l|}{ Metabolites } \\
\hline & & SPI-enol & SPI-ketohydroxy & SPI-monohydroxy & SPI-enol-glucoside \\
\hline & Mean $\mathrm{C} \pm \mathrm{SD} \mathbf{n}=\mathbf{3}$ & Mean C \pm SD $\mathbf{n}=3$ & Mean $\mathrm{C} \pm \mathrm{SD} \mathbf{n}=\mathbf{3}$ & Mean $\mathrm{C} \pm \mathrm{SD} \mathbf{n}=\mathbf{3}$ & Mean $\mathrm{C} \pm \mathrm{SD} \mathrm{n}=3$ \\
\hline \multicolumn{6}{|c|}{ BASIL Ocimum basilicum L. } \\
\hline $0(1 \mathrm{~h})$ & $3.619 \pm 0.0056$ & $1.952 \pm 0.0061$ & $0.162 \pm 0.0020$ & $0.008 \pm 0.0003$ & $0.007 \pm 0.0002$ \\
\hline 1 & $1.968 \pm 0.0049$ & $1.280 \pm 0.0050$ & $0.359 \pm 0.0036$ & $0.006 \pm 0.0002$ & $0.037 \pm 0.0011$ \\
\hline 2 & $2.033 \pm 0.0051$ & $0.814 \pm 0.0048$ & $0.495 \pm 0.0065$ & $<$ LOQ & $0.067 \pm 0.0022$ \\
\hline 3 & $0.447 \pm 0.0036$ & $0.542 \pm 0.0032$ & $0.416 \pm 0.0041$ & $<$ LOQ & $0.063 \pm 0.0013$ \\
\hline 7 & $0.024 \pm 0.0021$ & $0.184 \pm 0.0024$ & $0.237 \pm 0.0035$ & $<$ LOQ & $0.081 \pm 0.0025$ \\
\hline 14 & $0.010 \pm 0.0012$ & $0.044 \pm 0.0021$ & $0.193 \pm 0.0023$ & $<$ LOQ & $0.061 \pm 0.0039$ \\
\hline 21 & $0.002 \pm 0.0005$ & $0.027 \pm 0.0009$ & $0.095 \pm 0.0014$ & $<$ LOQ & $0.072 \pm 0.0026$ \\
\hline \multicolumn{6}{|c|}{ PEPPERMINT Mentha $\times$ piperita $\mathrm{L}$. } \\
\hline $0(1 \mathrm{~h})$ & $3.830 \pm 0.0060$ & $2.221 \pm 0.0053$ & $0.076 \pm 0.0038$ & $0.006 \pm 0.0001$ & $0.014 \pm 0.0004$ \\
\hline 1 & $2.530 \pm 0.0051$ & $0.683 \pm 0.0024$ & $0.779 \pm 0.0051$ & $0.006 \pm 0.0002$ & $0.011 \pm 0.0002$ \\
\hline 2 & $3.330 \pm 0.0047$ & $0.238 \pm 0.0032$ & $0.666 \pm 0.0048$ & $<$ LOQ & $0.005 \pm 0.0001$ \\
\hline 3 & $0.733 \pm 0.0022$ & $0.269 \pm 0.0019$ & $0.588 \pm 0.0034$ & $<\mathrm{LOQ}$ & $0.065 \pm 0.0008$ \\
\hline 7 & $0.020 \pm 0.0008$ & $0.011 \pm 0.0002$ & $0.041 \pm 0.0025$ & $<$ LOQ & $0.034 \pm 0.0003$ \\
\hline 14 & $0.008 \pm 0.0003$ & $<\mathrm{LOQ}$ & $0.009 \pm 0.0002$ & $<\mathrm{LOQ}$ & $0.037 \pm 0.0004$ \\
\hline 21 & $0.004 \pm 0.0002$ & $<$ LOQ & $0.010 \pm 0.0003$ & $<$ LOQ & $0.015 \pm 0.0002$ \\
\hline \multicolumn{6}{|c|}{ SAGE Salvia officinalis L. } \\
\hline $0(1 \mathrm{~h})$ & $3.904 \pm 0.0069$ & $1.868 \pm 0.0033$ & $0.077 \pm 0.0008$ & $0.010 \pm 0.0003$ & $0.006 \pm 0.0002$ \\
\hline 1 & $3.001 \pm 0.0065$ & $0.699 \pm 0.0026$ & $0.538 \pm 0.0058$ & $0.007 \pm 0.0002$ & $0.005 \pm 0.0001$ \\
\hline 2 & $2.795 \pm 0.0051$ & $0.689 \pm 0.0024$ & $0.500 \pm 0.0052$ & $<$ LOQ & $0.006 \pm 0.0001$ \\
\hline 3 & $0.710 \pm 0.0013$ & $0.178 \pm 0.0016$ & $0.418 \pm 0.0021$ & $<$ LOQ & $<\mathrm{LOQ}$ \\
\hline 7 & $0.134 \pm 0.0011$ & $0.161 \pm 0.0017$ & $0.091 \pm 0.0012$ & $<$ LOQ & $<$ LOQ \\
\hline 14 & $0.097 \pm 0.0009$ & $0.198 \pm 0.0019$ & $0.048 \pm 0.0011$ & $<$ LOQ & $<$ LOQ \\
\hline 21 & $0.042 \pm 0.0006$ & $0.041 \pm 0.0008$ & $0.039 \pm 0.0009$ & $<$ LOQ & $<$ LOQ \\
\hline
\end{tabular}

Table 2. Fate of spirotetramat in three species of herbs. Mean $\mathrm{C}-$ mean concentration for $\mathrm{n}=3(\mathrm{mg} / \mathrm{kg}) \pm \mathrm{SD}-$ standard deviation $(\mathrm{mg} / \mathrm{kg})$, LOQ - limit of quantification $(\mathrm{mg} / \mathrm{kg})$.

Drying is a simple traditional method of herbs preservation ${ }^{29}$. This procedure demonstrated different effectiveness because it has been found to reduce clethodim and clethodim sulfoxide residues and concentrate cletho$\operatorname{dim}$ sulfone $(\mathrm{PFs}>2)$. However, total clethodim were in the range of $\mathrm{PFs}=0.36-0.38$. Meanwhile, spirotetramat and spirotetramat B-ketohydroxy residues were concentrated (total PFs $=1.13-1.50$ ). The recorded decreases in pesticides were attributed to evaporation of their residues during drying, while the increase in residue levels was most likely due to weight changes during the process.

This phenomenon may be explained due to temperature in hot air drying caused thermal decomposition of clethodim (degradation point, $100.5^{\circ} \mathrm{C}$ ). However, spirotetramat PF values of drying were more than 1. Spirotetramat (degradation point, $235^{\circ} \mathrm{C}$ ) residue content in dried herbs tended to increase because of volatilization of water during processing. This is with agreement with research of Kim et al.$^{38}$ who reported that pesticide concentration in processed agricultural product is higher than in raw agricultural product because drying leads to vaporization of water. In our earlier experiment, we have also reported processing factors above one for three pyrethroids (up to $\mathrm{PF}=1.76$ ) subjecting berry fruit the high temperatures ${ }^{37}$. Thermal processing did not affect the reduction of alpha-cypermethrin, deltamethrin and lambda-cyhalothrin, compounds with very high degradation point (from $248^{\circ} \mathrm{C}$ to $275^{\circ} \mathrm{C}$ ).

Interestingly, the lowest PFs values in this study were observed when raw commodity was washed before drying. The greatest loss of clethodim and spirotetramat was achieved after drying proceeded by washing, up to $99 \%$ (PFs $=0.01-0.07$ and PFs $=0.01-0.27$, respectively). The residues of clethodim sulfoxide and SPI-enol residues were reduced up to $81 \%$ and $70 \%$, respectively. However, clethodim sulfone and SPI-ketoxydroxy after drying regardless of the use of washing in preparation of herbs were more than those in raw plants showing concentration factor above 1 . The overall results showed that total clethodim and total spirotetramat residues in dried basil, peppermint and sage were lower than those in unprocessed herbs (up to $86 \%$ and $73 \%$ of reduction, respectively).

The results demonstrated that washing played very important role in removing residues. This explains that water soluble clethodim (solubility in water at $20^{\circ} \mathrm{C}, 5450 \mathrm{mg} / \mathrm{L}$ and octanol-water partition coefficient $\log \mathrm{P}=4.14$ ) was more easily removed than spirotetramat (solubility in water at $20^{\circ} \mathrm{C}, 55 \mathrm{mg} / \mathrm{L}, \log \mathrm{P}=2.51$ ). The larger scope of processing factors proved washing prior to starting the drying process was effective step in removing pesticides. Many factors affected the removal of residue levels e.g. physicochemical properties and systemic character of the pesticides and allowed to make assumptions to explain the difference in the processing factors. These results were similar to the findings of Keikotlhaile ${ }^{22}$ who reported that the concentration of pesticide in processed product is related to solubility, volatility, polarity and thermal decomposition. The loss of residue

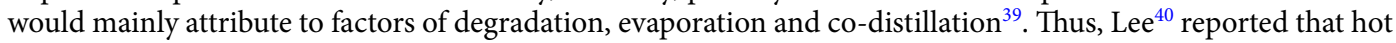


(a)

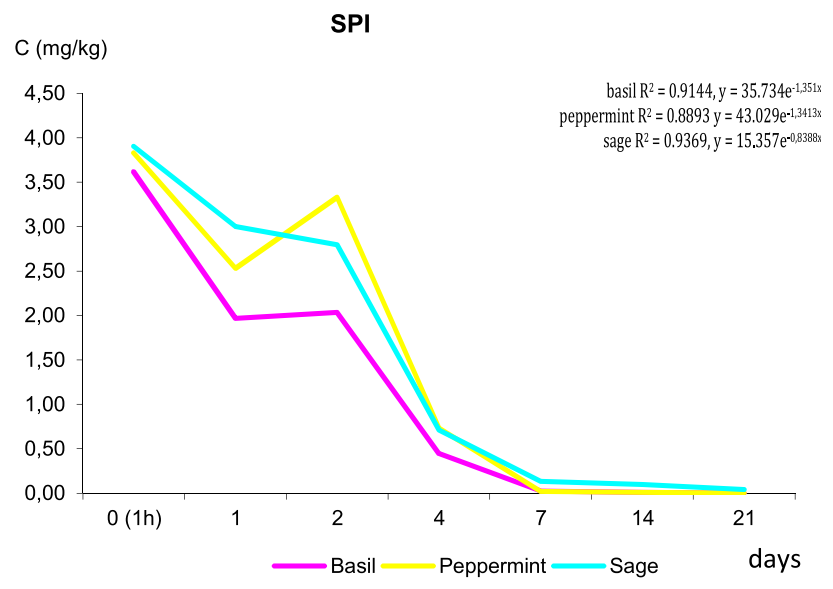

(b)

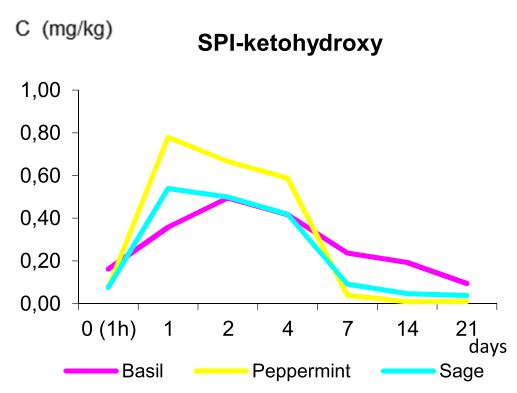

(c)

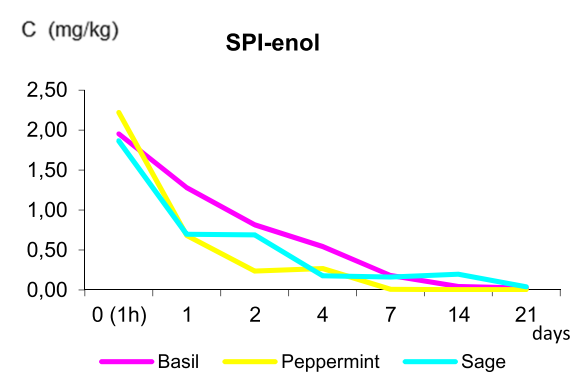

(d)

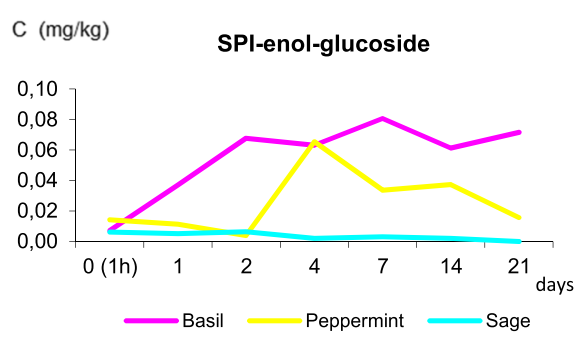

Figure 2. Changes in the concentration of spirotetramat (SPI) in three species of herbs. (a) SPI, (b) SPIketohydroxy, (c) SPI-enol, (d) SPI-enol-glucoside.

air drying eliminated $20-30 \%$ of azoxystrobin in ginseng products, while Mergnat et al. ${ }^{41}$ found that industrial dehydration reduced phosalone levels in apples by over $80 \%$.

Previously, we created a comprehensive database on $160 \mathrm{PFs}$ (processing/pesticide/product combination) for fruit and vegetables after different processing treatments previously. Water (PFs $=0.09-0.94)$, mechanical $(\mathrm{PFs}=0.13-0.32)$ and thermal $(\mathrm{PFs}=0.02-0.57)$ processing were very effective in reduction of pesticides in berry fruits, Brassica and fruit vegetables ${ }^{37}$. Special attention has been paid to finding the relationship between the efficiency of the technological process and selected physico-chemical properties of active substances. We proved that the key parameters affecting the removal effectiveness were physico-chemical properties of substance i.e. solubility, polarity, degradation point. 


\begin{tabular}{|c|c|c|c|c|c|c|c|c|c|c|c|c|}
\hline \multicolumn{3}{|l|}{ Herbal plant } & CLE & CLE-sulfone & $\begin{array}{l}\text { CLE- } \\
\text { sulfoxide }\end{array}$ & $\begin{array}{l}\text { CLE } \\
\text { total* }\end{array}$ & SPI & $\begin{array}{l}\text { SPI- } \\
\text { ketohydroxy }\end{array}$ & SPI-enol & $\begin{array}{l}\text { SPI- } \\
\text { monohydroxy }\end{array}$ & $\begin{array}{l}\text { SPI-enol- } \\
\text { glucoside }\end{array}$ & $\begin{array}{l}\text { SPI } \\
\text { total* }\end{array}$ \\
\hline \multirow{4}{*}{$\begin{array}{l}\text { BASIL Ocimum } \\
\text { basilicum L. }\end{array}$} & \multicolumn{2}{|c|}{$\begin{array}{l}\text { Initial C (\% of } \\
\text { parent substance) }\end{array}$} & 3.897 & $0.246(6 \%)$ & $1.965(50 \%)$ & 6.108 & 3.619 & $0.162(4 \%)$ & $1.952(54 \%)$ & $0.008(0.2 \%)$ & $0.007(0.2 \%)$ & 5.748 \\
\hline & \multirow{3}{*}{$\mathrm{PF}$} & $\mathrm{W}$ & 0.59 & 0.84 & 0.74 & 0.49 & 0.18 & 0.68 & 0.67 & 0.52 & 0.54 & 0.65 \\
\hline & & $\mathrm{D}$ & 0.06 & 2.05 & 0.30 & 0.38 & 1.57 & 0.61 & 1.69 & 0.01 & 0.01 & 1.13 \\
\hline & & $\mathrm{W}+\mathrm{D}$ & 0.01 & 1.63 & 0.23 & 0.14 & 0.01 & 0.39 & 1.08 & - & - & 0.29 \\
\hline \multirow{4}{*}{$\begin{array}{l}\text { PEPPERMINT } \\
\text { Mentha } \times \text { piperita L. }\end{array}$} & \multicolumn{2}{|c|}{$\begin{array}{l}\text { Initial C ( } \% \text { of } \\
\text { parent substance) }\end{array}$} & 4.251 & $0.219(5 \%)$ & $1.948(46 \%)$ & 6.418 & 3.830 & $0.076(2 \%)$ & $2.221(58 \%)$ & $0.006(0.2 \%)$ & $0.014(0.4 \%)$ & 6.147 \\
\hline & \multirow{3}{*}{$\mathrm{PF}$} & $\mathrm{W}$ & 0.69 & 0.74 & 0.88 & 0.53 & 0.45 & 0.53 & 0.62 & 0.05 & 0.40 & 0.68 \\
\hline & & $\mathrm{D}$ & 0.15 & 2.12 & 0.55 & 0.36 & 1.34 & 0.45 & 1.32 & - & 0.01 & 1.50 \\
\hline & & $\mathrm{W}+\mathrm{D}$ & 0.07 & 1.35 & 0.34 & 0.18 & 0.27 & 0.30 & 0.13 & - & - & 0.27 \\
\hline \multirow{4}{*}{$\begin{array}{l}\text { SAGE Salvia } \\
\text { officinalis L. }\end{array}$} & \multicolumn{2}{|c|}{$\begin{array}{l}\text { Initial C (\% of } \\
\text { parent substance) }\end{array}$} & 4.197 & $0.221(5 \%)$ & $2.437(58 \%)$ & 6.856 & 3.904 & $0.077(2 \%)$ & $1.868(48 \%)$ & $0.010(0.2 \%)$ & $0.006(0.1 \%)$ & 5.865 \\
\hline & \multirow{3}{*}{$\mathrm{PF}$} & $\mathrm{W}$ & 0.45 & 0.90 & 0.76 & 0.54 & 0.47 & 0.85 & 0.64 & 0.73 & 0.43 & 0.59 \\
\hline & & $\mathrm{D}$ & 0.12 & 2.09 & 0.54 & 0.37 & 1.26 & 0.72 & 2.60 & 0.15 & 0.01 & 1.17 \\
\hline & & $\mathrm{W}+\mathrm{D}$ & 0.02 & 1.36 & 0.19 & 0.15 & 0.20 & 0.31 & 1.31 & - & - & 0.31 \\
\hline
\end{tabular}

Table 3. Processing factors of clethodim and spirotetramat and their metabolites in herbs. Initial $\mathrm{C}$ - concentration obtained after $1 \mathrm{~h}$ of pesticide application in $\mathrm{mg} / \mathrm{kg}$. *sum of parent compound and metabolites. “-” processing factors not estimated due to complete reduction of substance. PF - processing factor. $\mathrm{W}$ - washing. D - drying. W $+\mathrm{D}$ - washing and drying.

The results of the present research focused on herbal matrices might complement European databases of PFs (i.e. EFSA, BfR) which contain data mainly for fruit/vegetables. The overall PFs for CLE-total and SPI-total in the final herb product were in the range of PFs $=0.14-0.18$ and PFs $=0.27-0.31$, respectively. Significant reduction of the initial concentration levels in basil, peppermint and sage in the range of $69-86 \%$ indicates that these herbs are safer to consumers ${ }^{42}$. Thus, combination of washing prior drying is very important practice in herbal plant preservation.

\section{Conclusion}

In the present work, valuable information regarding the metabolic profile of herbicide CLE and insecticide SPI in herbs during plants growing and processing was provided. Our findings predict the safe application of clethodim and spirotetramat at the recommended dosage to protect herbal plants and provide more understanding of herbicide and insecticide behavior in herbs.

These results will supplement the PF database in reference to herbs and might provide more accurate risk assessments of the cyclohexanedione herbicide and the tetramic acid insecticide.

\section{Material and Methods}

Pesticide standards and solvents. The analytical standards of CLE and its two metabolites CLE sulfone, CLE sulfoxide, and SPI and its four metabolites SPI-enol, SPI-keto-hydroxy, SPI-mono-hydroxy, SPIenol-glucoside ( $<99.0 \%$ purity) were obtained from Dr. Ehrenstorfer (Augsburg, Germany). All reagents used pesticide residue grade and were obtained from J.T. Baker (Deventer, Holland). More details in Supplementary Information.

Greenhouse trials. The greenhouse trial was performed under controlled conditions located in Bialystok, Poland where no pesticides were applied in the past five years. Herbal plants were cultivated during the agricultural season from June to September 2018. The greenhouse was divided into $15 \mathrm{~m}^{2}$ experimental plots, which were separated by a $1 \mathrm{~m}$ buffer zone between plots to minimize possible cross-contamination between treatments. The treatment included herbal dynamic test treatment (fate), three terminal residual test treatments (processing) and one control (without pesticides) (Fig. 3). Clethodim $\left(120 \mathrm{~kg} / \mathrm{m}^{3}(13 \%)\right)$ and spirotetramat $\left(100 \mathrm{~kg} / \mathrm{m}^{3}(9.35 \%)\right)$ were applied on basil (Ocimum basilicum L.), peppermint (Mentha $\times$ piperita L.) and sage (Salvia officinalis L.) were sprayed with manual sprayer at the recommended dose ( $80 \mathrm{~g}$ and $45 \mathrm{~g}$ of active ingredient per hectare, respectively) during herb grow at leaf development stage $(\mathrm{BBCH} 11-29$ from the first leaf stage to the end of the tillering phase). The temperature in the greenhouse ranged from 14 to $33^{\circ} \mathrm{C}$ and humidity ranged from $75 \%$ to $100 \%$ from the day of spraying until harvest. The samples from each treatment were collected separately (Fig. 3). A minimum of $200 \mathrm{~g}$ of representative herbal plants and soil samples were collected randomly at approximately $1 \mathrm{~h}$ (calculated as the initial concentration), 1st, 2nd, 3rd, 7th, 14th and 21th days (terminal concentration) after spraying.

Sample preparation and processing. The herbal plants immediately after collecting were brought to the analytical laboratory in the same day. The samples for dissipation kinetics without any processing operation were thoroughly homogenized using laboratory blender. The samples for processing study were processed within $24 \mathrm{~h}$ after being collected from the greenhouse to determine the changes in clethodim and spirotetramt concentrations in herbs (Fig. 4). 


\begin{tabular}{|l|l|l|}
\hline Fate (1) & Fate (2) & Fate (3) \\
\hline Processing W (1) & Processing W (2) & Processing W (3) \\
\hline Processing D (1) & Processing D (2) & Processing D (3) \\
\hline Processing W+D (1) & Processing W+D (2) & Processing W+D (3) \\
\hline Control (1) & Control (2) & Control (3) \\
\hline
\end{tabular}

Figure 3. Experimental design of research for each herb. W - washing, D - drying, W + DD - washing plus drying.

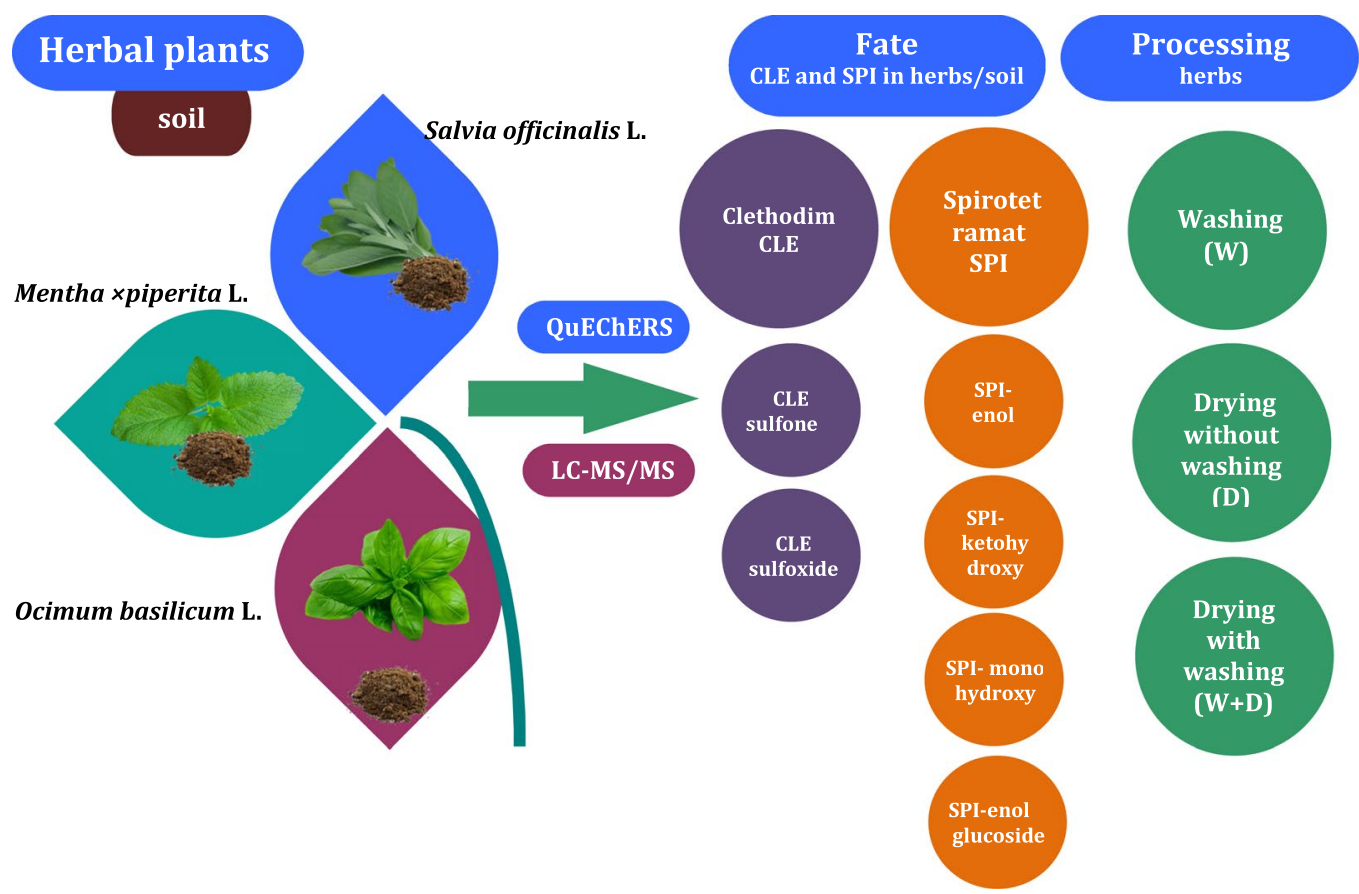

Figure 4. Sample preparation scheme.

In this study, three methods of decontamination were used: washing (W), drying (D), washing and drying $(\mathrm{W}+\mathrm{D})$. For this purpose, samples immediately after sampling were subjected to washing prior drying process, with and without previous pre-treatment (Fig. 1). Herbs were washed under running tap water at temperature app. $20^{\circ} \mathrm{C}$ for $1 \mathrm{~min}$, gently shaken to remove excess moisture and then gently dried with a paper towel. Unwashed and washed fresh herbal plants were subjected to the drying processes. Herbs were dried in a oven with ventilation at $50^{\circ} \mathrm{C}$ and were proceeded for $5 \mathrm{~h}$. Each treatment was carried out in triplicate. After that, washed (W), dried (D), washed and dried (W+D) samples were blended and taken to analysis.

Pesticide extraction and purification. The modified quick, easy, cheap, effective, rugged and safe (QuEChERS) method was used for extraction and purification of pesticide residues in fresh/processed herbal and soil samples according to EN 15662:2018 ${ }^{43}$. Analytical procedure was previously reported by Rutkowska et $a{ }^{44}$. More details in Supplementary Information.

Instrumental analysis. Chromatographic separation was carried out with an Eksigent Ultra LC-100 (Eksigent Technologies, Dublin, CA, USA) liquid chromatography (LC-MS/MS) equipped with a Kinetex XB- $\mathrm{C}_{18}$ column $(1.7 \mu \mathrm{m}, 2.1 \times 50 \mathrm{~mm})$ (Phenomenex) analytical column, maintained at $40^{\circ} \mathrm{C}$ during the experiments system was operated. More details in Supplementary Information.

Method validation. Recovery test was performed using spiked herb samples (fresh/dried) at four different concentration levels of selected pesticides $(0.001,0.1,1.0$ and $5.0 \mathrm{mg} / \mathrm{kg})$ in triplicate. Linearity was assessed via the determination coefficient $\left(\mathrm{R}^{2}\right)$ at five points ranging from 0.005 to $2.0 \mathrm{mg} / \mathrm{kg}$. The sensitivity was evaluated by determining the limit of detection (LOD) and the limit of quantification (LOQ) according to Document No. SANTE/1813/2017 34 . More details in Supplementary Information. 
Dissipation kinetics. The dissipation kinetics of CLE and SPI during different species herbal plants growth was estimated using first-order kinetics equation. The persistence of each compound expressed in terms of half-life $\left(t_{1 / 2}\right)$ was measured. The following two equations were used: Eq. $1 . C_{t}=C_{0} e^{-k t}$ and Eq. 2 . $t_{1 / 2}=\ln 2 / k$, where $\mathrm{C}_{\mathrm{t}}$ - concentration of the pesticide residues $(\mathrm{mg} / \mathrm{kg})$ at time $\mathrm{t}$ (days, $\mathrm{C}_{0}$ - initial concentration after $1 \mathrm{~h}(\mathrm{mg} /$ $\mathrm{kg}$ ) and $\mathrm{k}$ - the dissipation rate constant (per day).

Processing factor. The processing factor are calculated and considered by the Joint FAO/WHO Meeting on Pesticide Residues (JMPR) as follows: Processing factor $(\mathrm{PF}=$ Residue after processing $(\mathrm{mg} / \mathrm{kg}) /$ Residue before processing $(\mathrm{mg} / \mathrm{kg})$. The PF values below 1 (i.e., reduction factor) indicate a reduction of residues in a processed commodity, whereas the values above 1 (i.e., concentration factor) indicate concentration effects from the processing procedures. The unprocessed herb samples obtained from supervised field trial with initial deposits of pesticides were necessary to calculate the processing factors.

Received: 22 August 2019; Accepted: 23 December 2019;

Published online: 28 January 2020

\section{References}

1. Guldiken, B. et al. Phytochemicals of herbs and spices: Health versus toxicological effects. Food Chem. Toxicol. 119, 37-49 (2018).

2. Lozano, A. et al. Pesticide analysis in teas and chamomile by liquid chromatography and gas chromatography tandem mass spectrometry using a modified. J. Chrom. A. 1268, 109-122 (2012).

3. Malinowska, E. \& Jankowski, K. Pesticide residues in some herbs growing in agricultural areas in Poland. Environ. Monit. Assess. 187, 775 (2015).

4. Łozowicka, B. Health risk for children and adults consuming apples with pesticide residues. Sci. Total Environ. 502, 184-198 (2015).

5. EP 8.0 European Directorate for the Quality of Medicines and HealthCare European Pharmacopoeia, 8th edition, European Directorate for the Quality of Medicines and HealthCare, Strasbourg, France (2014).

6. CA Codex Alimentarius (2016). Food and Agriculture Organization of the United Nations http://www.fao.org/fao-whocodexalimentarius/codex-home/en/. (Accessed 22 August 2018).

7. Regulation (EC) No 396/2005 of the European Parliament and of the Council of 23 February 2005 on maximum residue levels of pesticides in or on food and feed of plant and animal origin and amending Council Directive 91/414/EEC.

8. Regulation (EC) No 1881/2006 of 19 December 2006 setting maximum levels for certain contaminants in foodstuffs.

9. EFSA European Food Safety Authority (2015) Scientific report of EFSA. The 2013 European Union report on pesticide residues in food. EFSA J 13(3):4038. http://www.efsa.europa.eu/sites/default/files/scientific_output/files/main_documents/4038.pdf. (Accessed 22 August 2018).

10. Rao, M. M., Kumar Meena, A. \& Galib, E. Detection of toxic heavy metals and pesticide residue in herbal plants which are commonly used in the herbal formulations. Environ. Monit. Assess. 181, 267-271 (2011).

11. Rutkowska, E., Łozowicka, B. \& Kaczyński, P. Modification of multi-residue QuEChERS protocol to minimize matrix effect and improve recoveries for determination pesticide residues in dried herbs followed by GC-MS/MS. Food Anal. Methods. 11, 709-724 (2017).

12. Sarkhail, P., Yunesian, M., Ahmadkhaniha, R., Sarkheil, P. \& Rastkari, N. Levels of organophosphorus pesticides in medicinal plants commonly consumed in Iran. DARU. 20,9 (2012).

13. Storelli, M. M. Evaluation of toxic metal ( $\mathrm{Hg}, \mathrm{Cd}, \mathrm{Pb})$, polychlorinated biphenyl (PCBs), and pesticide (DDTs) levels in aromatic herbs collected in selected areas of Southern Italy. Environ. Sci. Pollut. Res. 21, 946-953 (2014)

14. Tong, H., Tong, Y., Xue, J., Liu, D. \& Wu, X. Multi-residual Pesticide Monitoring in Commercial Chinese Herbal Medicines by Gas Chromatography-Triple Quadrupole Tandem Mass Spectrometry. Food Anal. Methods. 7, 135-145 (2014).

15. Słowik-Borowiec, M. et al. Detection of herbicide residues in peppermint using QuEChERS technique. Prog. Plant Prot. 44, $1142-1144$ (2013).

16. Boxall, A. B. A., Sinclair, C. I., Fenner, K., Kolpin, D. W. \& Maund, S. J. When synthetic chemicals degrade in the environment. Environ. Sci. Technol. 1, 369A-375A (2004).

17. You, X., Liang, L. \& Liu, F. Dissipation and residues of clethodim and its oxidation metabolites in a rape-field ecosystem using QuEChERS and liquid chromatography/tandem mass spectrometry. Food Chem. 143, 170-174 (2014).

18. Łozowicka, B., Mojsak, P., Kaczyński, P., Konecki, R. \& Borusiewicz, A. The fate of spirotetramat and dissipation metabolites in Apiaceae and Brassicaceae leaf-root and soil system under greenhouse conditions estimated by modified QuEChERS/LC-MS/MS. Sci. Total Environ. 603-604, 178-184 (2017).

19. Bandaranayake, W. M. Quality control, screening, toxicity, and regulation of herbal drugs. Mod. Phytomed. Turn Med. Plant Drugs. 2, 25-57 (2006)

20. Kaushik, G., Satya, S. \& Naik, S. N. Food processing a tool to pesticide residue dissipation - A review. Food Res. Int. 42, 26-40 (2009).

21. Karlovsky, P. et al. Impact of food processing and detoxification treatments on mycotoxin contamination. Mycotoxin Res. 32, 179-205 (2016)

22. Keikotlhaile, B. M., Spanoghe, P. \& Steurbaut, W. Effects of food processing on pesticide residue in fruits and vegetables; a metaanalysis approach. Food Chem. Toxicol. 48, 1-6 (2010).

23. Holland, P. T., Hamilton, D., Ohlin, B. \& Skidmore, M. W. Effects of storage and processing on pesticide residues in plant products. Pure Appl. Chem. 66, 335-356 (1994).

24. Łozowicka, B. \& Jankowska, M. Comparison of effects of technological water and thermal processing on pesticide removal in selected fruits and vegetables. J. Elem. 21, 99-111 (2016).

25. Timme, G. \& Walz-Tylla, B. Effects of food preparation and processing on pesticide residues in commodities of plant origin, Pesticide Residues in Food and Drinking Water. 121-148 (2004).

26. Kurzeja, E. et al. Changes in the antioxidant properties of herbs under the influence of steam sterilization and storage (in Polish). Bromat Chem. Toksykol. XLV, 980-984 (2012).

27. Brennan, J. G. Food processing handbook. (WILEY-VCH Verlag GmbH \& Co. KGaA, Weinheim, 2006).

28. Wachtel-Galor, S. \& Benzie, I. F. F. Herbal Medicine: An Introduction to Its History, Usage, Regulation, Current Trends, and Research Needs. In: Benzie IFF, Wachtel-Galor S, editors. Herbal Medicine: Biomolecular and Clinical Aspects. 2nd edition. Boca Raton (FL): CRC Press/Taylor \& Francis; (2011).

29. Pan, R. et al. Dissipation Pattern, Processing Factors, and Safety Evaluation for Dimethoate and ItsMetabolite (Omethoate) in Tea (Camellia Sinensis). PLoS ONE. 10, 1-12 (2015)

30. Abou-Arab, A. A. K. \& Abou Donia, M. A. Pesticide residues in some Egyptian spices and medicinal plants as affected by processing. Food Chem. 72, 439-445 (2001)

31. Ozbey, A. \& Uygun, U. Behaviour of some organophosphorus pesticide residues in thyme and stinging nettle tea during infusion process. Int. J. Food Sci. Tech. 42, 380-383 (2007). 
32. SANTE (2017) Document No. SANTE/11813/2017. Guidance document on analytical quality control and method validation procedures for pesticides residues analysis in food and feed. http://ec.europa.eu/food/plant/docs/plant_pesticides_mrl_guidelines_ wrkdoc_11945_en.pdf. (Accessed 22 August 2018).

33. PPDB: Pesticide Properties DataBase https://sitem.herts.ac.uk/aeru/ppdb/ (Accessed 8 November 2019).

34. Sandin-Espana, P., Sevilla-Moran, B., Lopez-Goti, C., Mateo-Miranda, M. \& Alonso-Prados, J. L. Rapid photodegradation of clethodim and sethoxydim herbicides in soil and plant surface model systems. Arab. J. Chem. 9, 694-703 (2016).

35. Zhang, Q. et al. Dissipation, residues and risk assessment of spirotetramat andits four metabolites in citrus and soil under field conditions by LC-MS/MS. Biomedical Chrom. 32, e4153 (2018).

36. Łozowicka, B., Jankowska, M., Hrynko, I. \& Kaczyński, P. Removal of 16 pesticide residues from strawberries by washing with tap and ozone water, ultrasonic cleaning and boiling. Environ. Monit. Assess. 188, 51 (2016).

37. Jankowska, M., Łozowicka, B. \& Kaczyński, P. Comprehensive toxicological study over 160 processing factors of pesticides in selected fruit and vegetables after water, mechanical and thermal processing treatments and their application to human health risk assessment. Sci. Total Environ. 652, 1156-1167 (2019).

38. Kim, N. H. et al. Meta-analytic approach to the effects of food processingtreatment on pesticide residues in agricultural products. Korean J. Pest. Sci. 20, 14-22 (2016).

39. Bajwa, U. \& Sandhu, K. S. Effect of handling and processing on pesticide residues in food- a review. J. Food Sci. Technol. 51, 201-220 (2014).

40. Lee, J. Y. et al. Processing factors of azoxystrobin in processed ginseng products. Korean J. Pest. Sci. 16, 222-229 (2012).

41. Mergnat, T., Fritsch, P., Saint-Joly, C., Truchot, E. \& Saint-Blanquat, G. Reduction in phosalone residue levels during industrial dehydration of apples. Food Addit. Contam. 12, 759-767 (1995).

42. Jankowska, M., Kaczynski, P., Hrynko, I. \& Lozowicka, B. Dissipation of six fungicides in greenhouse-grown tomatoes with processing and health risk. Environ Sci. Pollut. Res. Int. 23, 11885-900 (2016).

43. European Standard EN 15662:2018 Foods of plant origin - Multimethod for the determination of pesticide residues using GC-and LC-based analysis following acetonitrile extraction/partitioning and clean-up by dispersive SPE - Modular QuEChERS-method (2018).

44. Rutkowska, E., Łozowicka, B. \& Kaczyński, P. Three approaches to minimize matrix effects in residue analysis of multiclass pesticides in dried complex matrices using gas chromatography tandem mass spectrometry. Food Chem. 279, 20-29 (2019).

\section{Acknowledgements}

The Authors would like to thank to laboratory staff (Mrs. Ewa Rutkowska, Miss Izabela Hrynko, Mrs. Julia Rusiłowska, Mrs. Aleksandra Pietraszko and Miss Natalia Szymańska) for their assistance with this project. Special thanks go to Mr. Rafal Konecki, who helped in field trials during this research.

\section{Author contributions}

M.J. conceived and conducted the experiments; M.J. and P.K. analyzed the results, M.J. prepared the manuscript, B.Ł. supervised the experiment and draft of the manuscript.

\section{Competing interests}

The authors declare no competing interests.

\section{Additional information}

Supplementary information is available for this paper at https://doi.org/10.1038/s41598-020-58130-3.

Correspondence and requests for materials should be addressed to M.J.

Reprints and permissions information is available at www.nature.com/reprints.

Publisher's note Springer Nature remains neutral with regard to jurisdictional claims in published maps and institutional affiliations.

(c) (i) Open Access This article is licensed under a Creative Commons Attribution 4.0 International License, which permits use, sharing, adaptation, distribution and reproduction in any medium or format, as long as you give appropriate credit to the original author(s) and the source, provide a link to the Creative Commons license, and indicate if changes were made. The images or other third party material in this article are included in the article's Creative Commons license, unless indicated otherwise in a credit line to the material. If material is not included in the article's Creative Commons license and your intended use is not permitted by statutory regulation or exceeds the permitted use, you will need to obtain permission directly from the copyright holder. To view a copy of this license, visit http://creativecommons.org/licenses/by/4.0/.

(C) The Author(s) 2020 